\title{
Theoretical and Methodological Context of (Post)-Modern Econometrics and Competing Philosophical Discourses for Policy Prescription
}

\author{
Emerson Abraham Jackson ${ }^{1}$
}

DOI 10.1515/JHEEC-2017-0006

\begin{abstract}
This research article was championed as a way of providing discourses pertaining to the concept of "Critical Realism (CR)" approach, which is amongst many other forms of competing postmodern philosophical concepts for the engagement of dialogical discourses in the area of established econometric methodologies for effective policy prescription in the economic science discipline. On the whole, there is no doubt surrounding the value of empirical endeavours in econometrics to address real world economic problems, but equally so, the heavy weighted use and reliance on mathematical contents as a way of justifying its scientific base seemed to be losing traction on the intended focus of economics when it comes to confronting real world problems in the domain of social interaction. In this vein, the construction of mixed methods discourse(s), which favour that of CR philosophy is hereby suggested in this article as a way forward in confronting with issues raised by critics of mainstream economics and other professionals in the postmodern era.
\end{abstract}

Keywords: Theoretical / Methodological Intervention, Postmodern, Critical Realism, Econometrics

JEL Classification: A12, B50, C18

\footnotetext{
${ }^{1}$ Research Department, Bank of Sierra Leone, Freetown, Sierra Leone. Also, Doctoral Scholar, Centre of West African Studies, University of Birmingham, United Kingdom Phone: +232 78176272 / +44 7862703702

Email: emersonjackson69@gmail.com / EAJ392@bham.ac.uk / ejackson@bsl.gov.sl

Disclaimer: Views expressed in this article are those of the author and do not reflect that of any of the aforementioned institutions
} 
Emerson Abraham Jackson - Theoretical and Methodological Context of (Post)-Modern Econometrics and Competing Philosophical Discourses for Policy Prescription

\section{Introduction}

Economic science research has proved its existence by making use of myriad of (empirically oriented) methodologies to validate existing theories. The use of econometrics as a sub-discipline in mainstream economics to address complex models is thought to have existed for decades (Hoover, 2005 and Le Gall, 2007), while that of the less favoured and non-mathematical alternatives like critical realism continue to find its niche in influencing its existentiality, which is considered relevant for policy formulation. It is without doubt that Econometrics is perceived as a very relevant area in the discipline of economic science to help bring its scientific credence to the fore of critical discourse(s) with regard to its relevance for policy formulation.

(Empirical) Econometrics is an embracement of mathematics, statistics and economic theories to help shape human thoughts in the direction of simulating realities of real world economy through the construction of models. As emphasised by Hendry (2003: 4), econometrics has carved itself around the notion of models which have quantitative linkages for observed data series, with four perceived roles in economics: firstly, it creates a platform through its available technology means for summarising data, amongst myriad of information available to the practicing researcher for utilisation in support of sound economic judgment for policy analysis. Secondly, it provide the means for interpreting empirical information, and which in many cases is based on rational judgment(s). Thirdly, given the existence of competing theories, empirical econometrics provide the means through which model analysis can allow sound judgments to be made. Fourthly, it provide a means for the accumulation and development of knowledge through its power of forecasting events from economic phenomenon, and which Hendry (ibid) referred to as "raison d'être".

The rationale for this study is to provide critical discourses around theoretical and methodological contexts of econometric studies, with a view of applying post(modern) (philosophical) thinking as option for incorporating varied methods in the delivery of effective policy judgments. Having addressed the introductory background to empirical econometric research, subsequent sections have captured information relating to: the historical development and theoretical base of modern econometrics, econometric modelling and analysis, scientific basis for influencing policy decisions, critical realism and justification as a competing methodology, and finally conclusion.

\section{Historical Development and Theoretical Base in Econometrics}

Modern econometric modelling and analysis seem to have made great strides in terms of the direction and approach of empirical endeavours, but with emphasis on the mathematical / statistical contents as championed by some of its forefathers like Milton Friedman (Cord and Hammond, 2016). As critiques are being raised about its approach to addressing real world challenges, so too is the effort made towards the need for 
embracing social and extraneous components into model construction. This is quite true as expressed in "Dynamic Stochastic General Equilibrium (DSGE) and also Computable General Equilibrium (CGE) models which also account for social welfare factors affecting an entire economic system.

In as much as models and more so econometric methodologies are not truly representative of an entire economic system, it is believed that they can provide the enabling ground work for epistemological enquiries about the nature and the way forward in developing real world models. Postmodern econometric discourses is making it possible for economists to listen and where possible adapt their approaches as a way of evaluating model reconstruction and developments in the most positive way that support effective policy prescription.

\section{Scientific Base for Influencing Policy Decision(s)}

Empirical investigation which support the work of scientific act of falsification is evidenced throughout econometric research endeavours in economic policy formulation. In institutions like Central Banks, policy endeavours relating to topics concerned with price stability and exchange rate pass-through for example, are continually being pursued by researchers through use of scientific medium like EViews, STATA, SAS and many more to iterate around data in justify their efforts towards improving effective policy outcomes (Warburton and Jackson, forthcoming; Jackson. 2018a, 2018b, Jackson and Tamuke, 2018; Jackson et al, 2018 and Bangura et al, 2012; Tamuke et al, 2018).

In as much as many postmodern critics like Blaug (1977) may not totally support the mechanistic use of quantitative approach applied by economists to face life's realities (on account of their shortcomings in addressing social problems), one may also view efforts pursued by professionals as a step in the right direction by applying both theoretical and methodological mix in our understanding of the complex nature of the social world. The development and expansion of experimental research as a sub-discipline in mainstream economic science may be of great value to many critics on the heavy usage of mathematical contents by economist to address practical problems (Karlan, 2015). In this vein, it is possible that much needed concerns around theoretical application of economic concepts in different economic systems may no longer be seen as problematic given the fact that outcomes through experimentations create the enabling means for the establishment of dialogue.

\section{Critical Realism and Justification as a Competing Methodology}

In this section, discussion is focused on the case for 'Critical Realism' as a complementary methodology / philosophical paradigm to already established ones used in econometric studies. Developed by Maxwell and Mittapalli (2010), it is considered as a form of critical advances in human ontological quest for (provisional) knowledge, with diverse scope in support of human reality (Popper, 1963). 
Emerson Abraham Jackson - Theoretical and Methodological Context of (Post)-Modern Econometrics and Competing Philosophical Discourses for Policy Prescription

Practicing (modern) Economist like Boland (n/d) has for some years given his views on the methodology of critical realism, which in reality is considered very much needed to address dismal criticisms levied on the 'pseudo / non-scientific' state of economic science. The work of critical realists is based on the application of events as they happen in the real world as opposed to that which is dogmatically provided by empirical outcomes; in this view, such outcome(s) from empirical works can somehow present subjective view of events, simply on the grounds that information can be skewed towards the dominant way of thinking. As explained by Zachariadis et al (2013: 2), Critical Realism (CR) is typically concerned with the writings of Bhaskar $(1975,1978,1998)$ and others like Archer et al (1998), Fleetwood (1999) and Lawson (1997), embraces various methodological approaches from different philosophical positions by taking: 1. a critical stance towards the necessity and validity of current social arrangements; 2 . without following; 3. the extant paradigms; and 4. assumptions at face value (Mingers 2001: 248).

\subsection{Implications for Policy Prescription in Postmodern Econometric Studies}

Critical realism (CR) by its philosophy dictum, is different from other forms of (competing) postmodern thoughts in the area of research practices; emphasis on CR is believed to add value towards the ontological direction of postmodern development in econometrics, which also addresses gaps in the realities of policy prescription as dictated by current positivist / empiricist practices. Current methodological space in practical econometrics through its high powered mathematical intuition does not give enough scope for methodological mix within the wider discipline of economics to address unique space in the future direction of the discipline. According to Mongers (2004), this is thought to be lying between empiricism and interpretivism approaches, a supposedly good means to support objective discourses needed for effective policy prescription.

The benefit of CR in this study is its power to create objectivity in human thoughts, with no intent of diminishing existing positivist approaches in econometrics, but rather create the enabling means of viewing concepts differently in a bid to confronting the reality of human existentiality. As addressed in a study on triangulation by Jackson (2018c), the emergence of CR in the realm of quantitative model interpretation in the discipline of economics has already created an opportunity for the embracement of other professional views on how to perceive the world when it comes to dealing with the practicalities of policy implementation - one that is neither dominated by empiricist practice nor that of invalidated qualitative views of opposing professionals.

Critical Realism (CR) is not defined by any particular form of methodology (invariably, not a methodology); it create a stance on meta-theoretical position, a form of reflexive philosophical space supposedly concerned with the provision of philosophically informed account of science, which helps to inform developments in empirical investigations. Ontological space in CR study is assumed to be stratified into three areas of thinking: the real, the actual, and the empirical (Bhaskar 1975, 1978 and Zachariadis et al, 2013). This 
is an embracing feature that brings practitioners into seeing the world in its reality (featuring structures, and mechanisms with enduring properties), while also ensuring events are generated by the structures and mechanisms, which then result into an observable or experimental phenomena. This trending synthesis in CR study can be viewed as causal mechanism, which enables different events to interact without diminishing the value that the other brings to the fore of enhancing practitioners' view of the world, particularly when it is intended to impact positively on policy implementation.

\subsection{Mixed Methods Intervention for Effective Policy Analysis}

As addressed by Jackson (2017 and 2018c), mixed methods approach is a very important element in the way forward for dynamic policy intervention in the economic science discipline, and particularly that which may seek to (positively) influence policy formulation in an entire economic system. Economics attachment to being more scientific seem to have lagged in terms of being truly realistic about its humanistic root in addressing dynamic events that impact on welfare (Robbin's, 1932). The notion of retroduction is more so relevant here, which also makes it possible to address validity as perceived in the area of quantitative and qualitative studies.

As excerpted from Zachariadis et al (2013), the concept of "Retroduction allows researchers to move between the knowledge of empirical phenomena as expressed through events to the creation of explanations (or hypothesizing) in ways that hold "ontological depth" and can potentially give some indications on the existence of unobservable entities (Downward and Mearman 2006)". This allows things to be seen more openly with critical views on how concepts are perceived with or without the interaction of mechanisms as witnessed here.

Figure 1: Retroduction Approach of Critical Realism in Knowledge Exploration

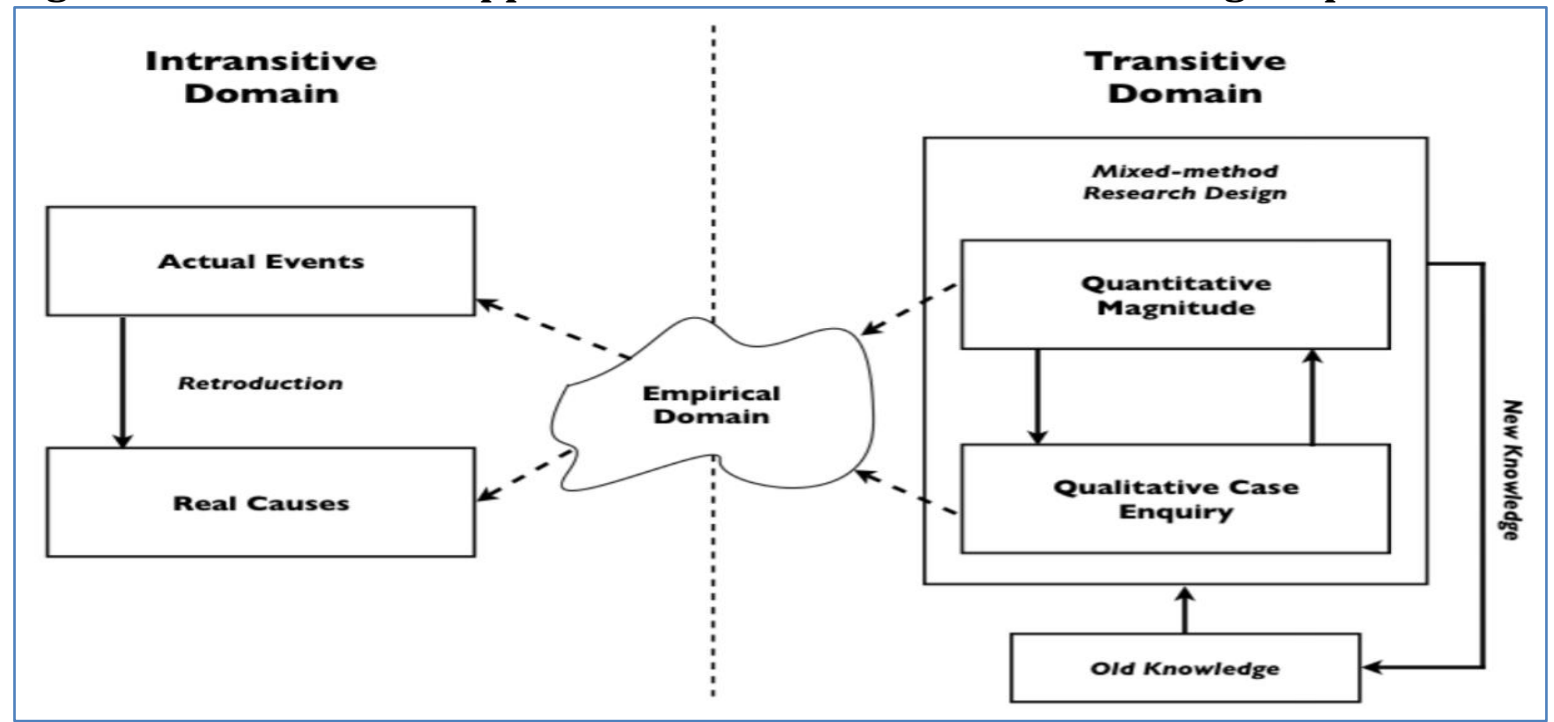

Source: Zachariadis et al, 2013

Figure 1 above provide the basis for the relevance of reduction approach as applied to critical realism in econometric methodology studies. Many (heterodox) researchers, both 
Emerson Abraham Jackson - Theoretical and Methodological Context of (Post)-Modern Econometrics and Competing Philosophical Discourses for Policy Prescription

practicing economists and real world practitioners (Downward and Mearman 2006; McEvoy and Richards 2006; Mingers 2004 and 2005; Mingers and Gill 1997; Wynn and Williams 2012) have argued in favour of the retroductionist approach, which create a blend between qualitative and quantitative approach in a bid to hypothesise the establishment of events (researchers) experienced in pursuit of ontological journey. As illustrated in Figure 1, the Transitive Domain seem to be the dominant force through which knowledge is addressed, but its link with the Intransitive Domain, typified by actual events and the retroduction approach makes it possible for blend of approaches to be considered in a bid to addressing effective outcomes, particularly in situations connected with policy implementation that requires not only that of empirical outcome, but also some constructive-intetpretivist view of real life problems.

As outlined in Figure 1, retroductionist approach does have implications for areas connected with validity of outcomes, Based on mixed methods literature (Creswell and Clark 2007; Venkatesh et al. 2013), there is possibility that this can be addressed more easily through a review of CR philosophy. According to Venkatesh et al (2013) and Zachariadis et al (2013), validity can be categorised into three distinct classes, which are somehow commonly used in quantitative and qualitative research designs; these typically include "design validity, measurement (or analytical) validity, and inferential validity".

Given the nature of the discourse, which involve mixed-methods philosophy, quantitative research approach to design validity broadly refers to internal (typically, the correlation of observable causation) and external (which is based on the generalisability of results) validity. Measurement validity on the other hand, is associated with data reliability (an area related to measurement error) and construct validity, typically describes the intended purpose for which variables selected can be measured. Last but not least is inferential validity; this relates to statistical conclusions and their sufficiency in supporting valid inferences.

Validity concept in qualitative research seem to have taken a more agreed view about its relevance to the scientific body of knowledge (Denzin and Lincoln 1994: Venkatesh et al. 2013). This then makes it possible for pro-qualitative researchers to pursue similar venture(s) in relation to common and established definitions for validity, which then focused on the design and execution (design validity) of qualitative study approach; accuracy of data collection and analysis, in a bid to achieving dependable, consistent, and plausible findings (an attribute of analytical validity); and, last but not least, an assessment of the overall quality of interpretation and inferences, which is akin to inferential validity (Zachariadis et al, 2013).

In as much as Econometrics have sought to address problems through complex mathematical model construction, for once, it is worthwhile that consideration is given to a reflection on the real world of its continued existence; in this case, the reality of having to deal with the vagaries of human actions will never be held constant, despite the assumption of Ceteris Paribus assumption (Jackson, 2017a). In this vein, one may think that a reflection on Schoonenboom's (2017: 1) three existing paradigms for mixed 
methods research, namely "dialectic stance, critical realism, and pragmatism", should be addressed with their inherent characteristics and limitations.

This can also be linked to Arrow's (1986: 5394) critic on his article titled: "Rationality of Self and Others in an Economic System". This article addresses a lot of critical concerns in relation to the methodology of economics in general and its sub-set, econometrics. One of such area is concerned with the 'Rational Expectation Theory' which is more about stochastic form of perfect foresight. Such critiques as addressed by Merton (1957) was done on the basis of self-fulfilling promise(s) advanced on the basis of dogmatic outcomes from forecasts produced by econometricians. Such criticism is also being championed by post-modern critics like Boland (n/d).

\section{Conclusion}

In view of the discussion that has emanated from this work, it is worthwhile to note that the works of empirical economics (through its machinery of econometrics) is still highly valued by both traditional and heterodox economists and also, critical policy oriented researchers. The unidirectional approach (empiricist / positivist inclination) that had long being practiced to prove the scientific space of economics is the challenge of its critics (Boland, n/d; Kirman, 1992; Klamer and McCloskey, 1989).

While it is still viewed as necessary to embrace empirical research as pursued in economics to affirm it scientific tradition, the new era of postmodern tradition have willingly embraced it, but also advocating research connection with the real world (reference to Figure 1). With this, CR as presented here on a competing research paradigm is no enemy to established empirical research work as already pursued in the field of econometrics study, which recognises mixture of qualitative and quantitative approaches, but also ensuring that continuous dialogue remain part of the journey of research endeavours, which invariably is sure to bring credibility to research outputs needed for policy formulation in the discipline of economics.

\section{References}

Archer, M., Bhaskar, R., Collier, A., Lawson, T., and Norrie, A. (1998). Critical Realism: Essential Readings, London: Routledge.

Arrow, K. (1986). Rationality of Self and Others in an Economic System. The Journal of Business, Vol. 59(4), Part 2: The Behavioral Foundations of Economic Theory: pp. S385-S399.

Bangura, M., Caulker, E. and Pessima, S. (2012). Exchange Rate Pass-Through to Inflation in Sierra Leone: A Structural Vector Autoregressive Approach. Journal of Monetary and Economic Integration, Vol. 12(1): pp. 93-123. 
Bhaskar, R. (1975). A Realist Theory of Science, Leeds, UK: Leeds Books.

Bhaskar, R. (1978). The Possibility of Naturalism, Sussex, UK: Harvester Press.

Bhaskar, R. (1998). "Philosophy and Scientific Realism", in Critical Realism: Essential Readings, M. Archer, R. Bhaskar, A. Collier, T. Lawson, and A. Norrie (eds.), London: Routledge, pp. 16-47

Blaug, M. (1997 ed). THE METHODOLOGY OF ECONOMICS or how economists explain it. Cambridge University Press: UK.

Boland, L. (n/d). Critical Realism vs Economic Rhetoric. Simon Fraser University. Available at: http://www.sfu.ca/ boland/realism.htm. (Accessed: 7th March, 2018).

Brandts, J. and Charness, G. (2011). The strategy versus the direct-response method: a first survey of experimental comparisons. Journal of Exp Econ, Vol.14:375-398. DOI 10.1007/s10683-011-9272-x.

Creswell, J. W., and Clark, V. L. P. (2007). Designing and Conducting Mixed Methods Research, Thousand Oaks, CA: Sage Publications.

Cord, R.A. and Hammond, D. (2016). Milton Friedman: Contributions to Economics and Public Policy. Oxford, UK: Oxford University Press.

Downward, P., and Mearman, A. (2006). "Retroduction as Mixed-Methods Triangulation in Economic Research: Reorienting Economics into Social Science”, Cambridge Journal of Economics (31:1), pp. 77-99

Fleetwood, S. (1999). "Situating Critical Realism in Economics"; in Critical Realism in Economics, S. Fleetwood (ed.), London: Routledge, pp. 127-135.

Flyvbjerg, B. (2004). Phronetic planning research: theoretical and methodological reflections. Planning Theory \& Practice, Vol. 5(3): pp. 283-306. DOI: $10.1080 / 1464935042000250195$.

Galton, F., (1886), Regression Towards Mediocrity in Hereditary Stature, Journal of the Anthropological Institute, 15, 246-63.

Hendry, D.F. (2003 ed). Dynamic Econometrics. Oxford and New York: Oxford University Press.

Hoover, Kevin D. (2005) The Methodology of Econometrics. Available at SSRN: https://ssrn.com/abstract=728683 or http://dx.doi.org/10.2139/ssrn.728683. (Accessed: 7th March 2018). 
Jackson, E.A. (2018a). On the question of the relevance of economics as a science: Postmodern filosifia critique. MPRA Working Paper No. 86185.

Jackson, E.A. (2018b): Jackson, Emerson Abraham, Comparison between Static and Dynamic Forecast in Autoregressive Integrated Moving Average for Seasonally Adjusted Headline Consumer Price Index. Available at SSRN: http://dx.doi.org/10.2139/ssrn.3162606.

Jackson, E.A and Tamuke, E. (2018). Probability Forecast Using Fan Chart Analysis: A Case of the Sierra Leone Economy. Journal of Advanced Studies in Finance, Vol. 9(1): pp. 34-44. ISSN 2068-8393. DOI: 10.14505//jasf.v9.1(17).04.

Jackson, E.A., Sillah, A. and Tamuke, E. (2018). Modelling Monthly Headline Consumer Price Index (HCPI) through Seasonal Box-Jenkins Methodology. International Journal of sciences, Vol. 7(1): pp. 51-56. DOI: 10.18483/ijSci.1507.

Jackson, E.A. (2018c) "Triangulation: A retroduction approach in the reorientation of social science research for Central Bank policy in Sierra Leone", African Journal of Economic and Management Studies, Vol. 9(2): pp. 266-271. https://doi.org/10.1108/AJEMS-012018-0034

Jackson, E. A. (2017a). Economic Methodology: Paradox of Ceteris Paribus (CP) Law in the Context of Sierra Leone. Method(e)s: African Review of Social Sciences Methodology, Vol. 2(1-2): pp. 31-40. DOI: 10.1080/23754745.2017.1354553.

Jackson, E.A. (2017). Practical Research Methods: A User-Friendly Guide to Mastering Research Techniques and Projects (Media Review). Journal of Mixed Methods Research, Vol. 11(3): pp. 417-418. (First Online, September, 2016). DOI: $10.1177 / 1558689816668103$.

Karlan, D.S. (2005) : Using Experimental Economics to Measure Social Capital And Predict Financial Decisions, Center Discussion Paper, No. 909, Yale University, Economic Growth Center, New Haven, CT.

Kirman, Alan P. (1992) 'Whom or What Does the Representative Individual Represent? Journal of Economic Perspectives, 6(2), Spring, pp. 117-36.

Klamer, A. and McCloskey, D. (1989). “The Rhetoric of Disagreemen”. Rethinking Marxism. Fall, 1989(2): pp. 140-162.

Lawson, T. (1997). Economics and Reality, London: Routledge. 
Emerson Abraham Jackson - Theoretical and Methodological Context of (Post)-Modern Econometrics and Competing Philosophical Discourses for Policy Prescription

Le Gall, P. (2007). A History of Econometrics in France: From Nature to Models. London and New York: Routledge, Taylor and Francis Group.

Magnus, Jan \& Mary S. Morgan (1987) The ET Interview: Professor J. Tinbergen in: 'Econometric Theory 3, (1987)117-142.

Maxwell, J. A., \& Mittapalli, K. (2010). Realism as a stance for mixed methods research. In A. Tashakkori \& C. Teddlie (Eds.), Sage handbook of mixed methods in social \& behavioral research (2nd ed., pp. 145-167). Thousand Oaks, CA: Sage.

McEvoy, P., and Richards, D. 2006. "A Critical Realist Rationale for Using a Combination of Quantitative and Qualitative Methods," Journal of Research in Nursing (11:1), pp. 6678.

Maxwell, J. A. (2012). A realist approach for qualitative research. Thousand Oaks, CA: Sage.

Merton, R.K. (1957). The Self-fulfilling Promises. In Social Theory and Social Structure. Rev. and enlarged ed, Glencoe. III: Free Press.

Mingers, J. (2001). "Combining IS Research Methods: Towards a Pluralist Methodology". Information Systems Research (12:3), pp. 240-259.

Mingers, J. (2004). "Real-izing Information Systems: Critical Realism as an Underpinning Philosophy for Information Systems," Information and Organization (14:2), pp. 87-103.

Mingers, J. (2005). "A Critique of Statistical Modelling in Management Science from a Critical Realist Perspective: Its Role Within Multi-methodology," Journal of the Operational Research Society (57:2), pp. 202- 219.

Mingers, J., and Gill, A. (Eds.). 1997. Multi-methodology, Chichester, UK: John Wiley \& Sons Ltd.

Pollock, D.S.G. (2014). Econometrics: An historical guide for the uninitiated. University of Leicester, Working Paper No. 14/05.

Popper, K. (1963). Conjectures and refutations: The growth of scientific knowledge. London, UK: Routledge.

Robins, L. (1932). An essay on the nature and significance of economic science. Macmillan and Co., Limited: London.

Samuelson, P.A., T.C. Koopmans and J.R.N. Stone (1954), "Report of the Evaluative Committee for Econometrica". Econometrica, 22: pp. 141-146. 
Schoonenboom, A. (2017). A Performative Paradigm for Mixed Methods Research. Journal of Mixed Methods Research, Online First: pp. 1-17. DOI: 10.1177/1558689817722889.

Tamuke, E., Jackson, E.A. and Sillah, A. (2018). Forecasting inflation in Sierra Leone using ARIMIA and ARIMAX: A comparative evaluation. Theoretical and Practical Research in Economic Field, (Volume IX, Summer), 1(17): pp. 63-74.

Venkatesh, V., Brown, S. A., and Bala, H. 2013. "Bridging the Qualitative-Quantitative Divide: Guidelines for Conducting Mixed Methods Research in Information Systems," MIS Quarterly (37:1), pp. 21-54.

Warburton, C.E.S. and Jackson, E.A. (forthcoming). Monetary Policy Responses to Exogenous Perturbations: Energy Shocks and Monetary Policy in a Small Open Economy (Sierra Leone, 2007-2018).

Wynn, D., and Williams, C. K. 2012. "Principles for Conducting Critical Realist Case Study Research in Information Systems,” MIS Quarterly (36:3), pp. 787-810.

Zachariadis, M., Scott, S. and Barrett, M. (2013). Methodological implications of critical realism for mixed-methods research. MIS Quarterly Vol. 37(3): pp. 855-879. 